\title{
LA ARGUMENTACIÓN EN VALSES Y OTRAS FALSAS CONFESIONES, DE BLANCA VARELA
}

\section{BLANCA VARELA'S ARGUMENTATION IN WALTZES AND OTHER FALSE CONFESSIONS}

\author{
Camilo Fernández Cozman \\ Universidad de Lima \\ crferna@ulima.edu.pe
}

\section{RESUMEN}

Un aspecto que se viene discutiendo en el ámbito de los estudios literarios es la dimensión argumentativa de algunos textos poéticos. El propósito de este artículo es reconocer y analizar la estructura argumentativa de algunos poemas de Blanca Varela en Valses y otras falsas confesiones (1972), por ejemplo, “Vals del ángelus”. La idea es segmentar el poema de Varela tomando en cuenta el exordio, la argumentación y la peroración final; luego distinguir las provincias figurales ligadas a técnicas argumentativas a partir de los enfoques de Giovanni Bottiroli, Chaïm Perelman y Lucien Olbrechts-Tyteca. Por último, se trata de enlazar la estructura argumentativa del texto poético con la perspectiva de Walter Benjamin para poner de relieve cómo Varela cuestiona la invisibilización de la mujer en el mundo contemporáneo.

PALABRAS CLAVE: argumentación, poema, mujer, invisibilización, análisis

\section{ABSTRACT}

One aspect that has been discussed in the field of literary studies is the argumentative dimension of some poetic texts. The purpose of this article is to recognize and analyze the argumentative structure of some of Blanca Varela's poems in Waltzes and Other False Confessions (1972), for example, “Angelus Waltz". The idea is to segment Varela's poem taking into account the exordium, the argumentation, and the final peroration; then distinguish the figurative provinces linked to argumentative techniques from the approaches of Giovanni Bottiroli, Chaïm Perelman, and Lucien OlbrechtsTyteca. Finally, it is about linking the argumentative structure of the poetic text with the perspective of Walter Benjamin to highlight how Varela questions the invisibility of women in the contemporary world.

KEYWORDS: argumentation, poem, woman, invisibility, analysis 
De acuerdo con la clasificación aristotélica, existen tres géneros discursivos: el judicial, el deliberativo y el epidíctico (Aristóteles, Retórica, 1358b10-20; Pernot, 2013). El primero supone el funcionamiento del discurso del abogado, es decir, del mecanismo de la acusación y de la defensa; sin duda, el tiempo que predomina es el pasado y se discute sobre lo justo frente a lo injusto. El segundo implica el discurso del político, en otras palabras, la presencia del consejo y de la disuasión; en este caso, el tiempo que prima es el futuro y se polemiza en torno a lo perjudicial y lo conveniente. El tercero evidencia el discurso del orador que busca demostrar cierta premisa a través del elogio o de la censura; aquí el tiempo que prepondera es el presente (aunque también se puede emplear el pasado o el futuro) y, en tal sentido, la controversia se desata acerca de lo bello frente a lo vergonzoso (Aristóteles, Retórica, 1358b20-25).

El término literatura, como bien se sabe, es de origen latino; sin embargo, tiene lazos con el género epidíctico, porque involucra la dimensión estética de la argumentación. En tal sentido, la poesía lírica es heredera del género epidíctico y, en ciertas ocasiones, puede tener una dimensión argumentativa. Tal es el caso de Poemas humanos (1939), de César Vallejo, o de Canto general (1950), de Pablo Neruda. Ambos poemarios tienen una ostensible dimensión política y, por lo tanto, incorporan creativamente el mecanismo de la argumentación.

El propósito de este ensayo es subrayar el papel de la argumentación en algunos poemas de Valses y otras falsas confesiones (1972), de Blanca Varela. Para ello, abordaremos dos enfoques en torno a la argumentación en el ámbito de la poesía. Luego dividiremos la producción poética de Varela con el fin situar nuestra investigación y, finalmente, abordaremos, desde el punto de vista argumentativo, un poema de Valses y otras falsas confesiones: "Vals del ángelus".

La primera perspectiva es la de Fernández Cozman (2012, 2014, 2016), quien analiza la naturaleza argumentativa de poetas como César Vallejo, Antonio Cisneros y José Watanabe. En el caso de la poesía de Vallejo, distingue un exordio, una argumentación, una narración (no siempre presente en todos los poemas) y una peroración final. Para ello, privilegia la dimensión política de algunos textos vallejianos como "La cena miserable" o “Los desgraciados", por ejemplo. Fernández Cozman $(2012,2014,2016)$ se sustenta en las propuestas de Bottiroli (1993), de Arduini (2000) y, sobre todo, de Perelman y OlbrechtsTyteca (2006) para analizar los procedimientos figurativos y las técnicas argumentativas que se manifiestan en la poesía de Vallejo, de Cisneros o de Delgado.

La segunda orientación es la de Parrilla Sotomayor (2018), quien se basa en Toulmin (2006), en Lakoff y Turner (1989) y en Lakoff y Johnson (2003) para plantear dos posibilidades: la argumentación en cuanto totalidad en el poema y la argumentación como fragmento que se halla inserto en el texto poético. Para cumplir con dicho propósito, Parrilla Sotomayor (2018) analiza poemas de Wistawa Szymborska, Amy Lowell, Nicanor 
Parra y Luis Rogelio Nogueras, entre otros. Además, el estudioso afirma que su objetivo central "consiste en demostrar que la argumentación es la secuencia prototípica que mejor contribuye a la exégesis de la isotopía temática en el texto poético" (párr. 4).

Pasemos a establecer una periodización de la poesía de Varela que, según la crítica especializada, se puede dividir en tres etapas (Fernández, 2010). La primera es la de los inicios y comprende Ese puerto existe y Luz de día. En este caso, se comprueba el uso del yo masculino para enmascarar estratégicamente la sensibilidad femenina: "Sé que estoy enfermo de un pesado mal, lleno de un agua amarga, de una inclemente fiebre que silba y espanta a quien la escucha" (Varela, 2016, p. 13). Dicha particularidad se encuentra en Ese puerto existe, donde se advierte la influencia de la lírica de Octavio Paz y del existencialismo de la posguerra. La segunda etapa evidencia la desmitificación de las instituciones oficiales (algunas asociadas a la dominación masculina y al patriarcado) y abarca dos poemarios: Valses y otras falsas confesiones y Canto villano. Por ejemplo, en “Lady's Journal", se cuestiona el rol de ama de casa asignado a la mujer: "el café será eterno / y el sol eterno / si no te mueves / si no despiertas / si no volteas la página / en tu pequeña cocina / frente a mi ventana" (Varela, 2016, pp. 135-136). El tercer periodo manifiesta la relevancia del cuerpo como tema de reflexión y comprende desde Ejercicios materiales hasta El falso teclado. Verbigracia, en El libro de barro se afirma: "Ahora el cuerpo es un arco y la flecha el aliento que aspira su forma. El corazón del eclipse, el viaje y el negro esplendor de la música carnal allí adentro, en el hueso del alma" (Varela, 2016, p. 194).

Pensamos que hay cuatro grandes líneas de investigación en torno a la poesía de Varela. La primera orientación explicita de qué manera esta poesía se sitúa en el contexto posterior a la Segunda Guerra Mundial y el influjo que en ella tuvieron la poética surrealista y el existencialismo (Castañón, 2007; Gazzolo, 2007; Oviedo, 2007; Paoli, 2007; Paz, 2007; Sobrevilla, 2007). La segunda perspectiva ubica a Varela en la tradición literaria peruana o latinoamericana enfatizando ciertos procedimientos como el yo fragmentado o la desmitificación de algunos tópicos de la cultura occidental, tales como el libro en tanto objeto de sabiduría (Fernández Cozman, 2010; Muñoz, 2007); además, dicha postura teórica aborda la presencia de un bestiario en la obra de Varela (Rodríguez Gutiérrez, 2008; Salazar, 2012). La tercera óptica metodológica evidencia la relación entre la poesía y la pintura sobre la base del estudio de las referencias a ciertas obras pictóricas en determinados poemas de Varela (Suárez, 2003). La cuarta línea de indagación se fundamenta en el enfoque de género para destacar cómo la poeta peruana realiza un cuestionamiento de la sociedad androcéntrica y del orden patriarcal (Huamán, 2007; Portocarrero, 2007; Reisz, 2007; Silva-Santisteban, 2007). 


\section{LA ARGUMENTACIÓN EN VALSES Y OTRAS FALSAS CONFESIONES}

Uno de los textos más representativos de Valses... es "A rose is a rose" (título inspirado en un poema de Gertrude Stein) donde Varela utiliza el argumento basado en el antimodelo (Perelman y Olbrechts-Tyteca, 2006) para cuestionar la rosa como símbolo de una estética caduca:

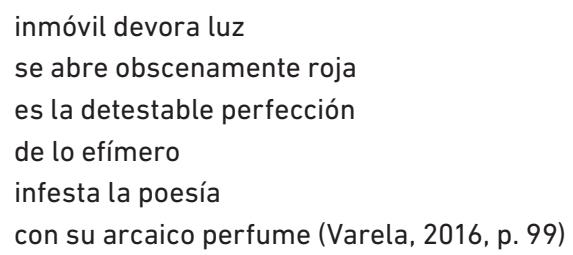

Aquí hay una controversia si notamos que, en la tradición poética peruana, se encuentra, por ejemplo, Travesía de extramares de Martín Adán que se solaza en la Rosa (con mayúscula) como metáfora de lo absoluto. Varela opone otra metáfora conceptual (Lakoff y Johnson, 2003): la rosa es estética caduca. Sin duda, la isotopía de la inmovilidad (vale decir, del anquilosamiento) que revela la siempre anhelada perfección es sometida a crítica por la poeta peruana. El tono refutativo del escueto poema evidencia lo que Perelman y Olbrechts-Tyteca (2006) llaman la elección de las calificaciones que "se manifiesta de la forma más aparente por el uso del epíteto, el cual resulta de la selección visible de una cualidad que se antepone y que debe complementar nuestro conocimiento del objeto" (p. 206). Al epíteto "arcaico perfume" hay que añadir la naturaleza argumentativa del oxímoron "detestable perfección" que se sitúa en la provincia figural de la negación (Bottiroli, 1993). Ello implica una toma de posición del hablante lírico; en realidad, una especie de diatriba contra la mencionada estética caduca, aspecto que se refuerza con la metáfora "infesta la poesía" para subrayar la secuela absolutamente negativa de la presencia de la rosa como ideal de belleza.

Otro texto relevante por su propósito argumentativo, en Valses..., es "Encontré":

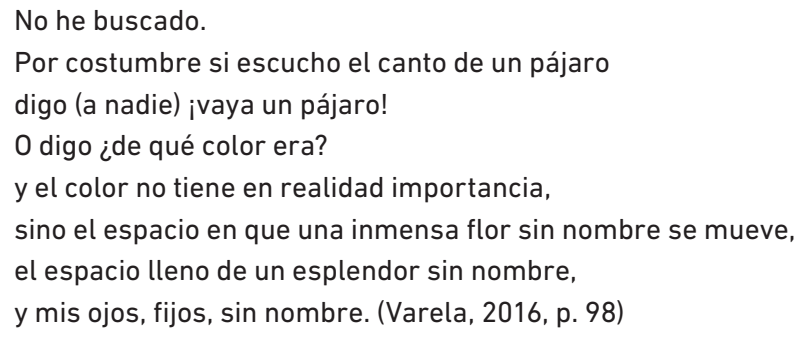

Aquí destacan las marcas del sujeto de la enunciación en el enunciado en la iteración del verbo digo. El locutor-personaje (Fernández, 2009, 2021) se dirige a un alocutario no representado y, por ello, configura un monólogo reflexivo. A diferencia del poema 
anterior, en este caso sobresale el argumento de la dirección: "llamemos a esta técnica el procedimiento de las etapas [cursivas añadidas]" (Perelman y Olbrechts-Tyteca, 2006, p. 452). Primero tenemos la negación inicial. Luego observamos el condicional con su antecedente y consecuente: si a, entonces, b. Después aparece el conector disyuntivo que precede al verbo y al planteamiento de la controversia a través de una pregunta. Finalmente, el locutor personaje enuncia su propia hipótesis. Así Varela se opone a la metáfora "nombrar es clasificar racionalmente", pues la poeta privilegia la experiencia subjetiva (léase, sin parámetros razonados ni rígidos) de percibir el espacio que da pleno sentido a los objetos del mundo. Por eso, el nombre del color, de la flor, del esplendor y de los ojos no posee ninguna importancia. Asimismo, hay una oposición conceptual entre el título del poema y el primer verso: el encuentro un tanto azaroso (valorado por Varela) frente a la búsqueda premeditada.

Ese cuestionamiento de ciertas metáforas estereotipadas (o catacresis) revela cómo Valses y otras falsas confesiones tiene una dimensión argumentativa y un tono refutativo indiscutibles. Ahora pasaremos al análisis de un texto muy representativo de dicho poemario.

\section{ANÁLISIS DE “VALS DEL ÁNGELUS”}

Este es uno de los poemas más típicamente argumentativos de Blanca Varela por el tono de diatriba contra la invisibilización de la mujer en el mundo contemporáneo. Meyer (2013) afirma que la retórica constituye "la negociación misma de la diferencia entre individuos sobre un tema dado" (p. 57). En "Vals del ángelus", poema en prosa, predomina el disenso: la locutora-personaje que visibiliza su carácter femenino increpa al alocutario representado su modo de proceder. Se trata de un auditorio constituido por un solo oyente y que es "la encarnación de un auditorio particular determinado" (Perelman, 2006, p. 85) que defiende la dominación masculina y relega a la mujer a un lugar deshonroso. El poema argumentativo posee tres partes: el introito (desde el inicio hasta "la que sangra todos los días del año"), la argumentación (desde "Así te he visto" hasta "cieno de ojos vaciados") y la peroración final (desde "Tu imagen en el espejo" hasta el final).

Analicemos el introito:

Ve lo que has hecho de mí, la santa más pobre del museo, la de la última sala, junto a las letrinas, la de la herida negra como un ojo bajo el seno izquierdo. Ve lo que has hecho de mí, la madre que devora sus crías, la que se traga sus lágrimas y engorda, la que debe abortar en cada luna, la que sangra todos los días del año. (Varela, 2016, p. 88)

Se trata de una argumentación basada en el enlace de sucesión y, en particular, en un nexo causal que actúa in absentia, pues se halla representado por la coma. En tal sentido, la estructura canónica hubiera podido ser la siguiente: "Ve lo que has hecho de mí porque 
soy la santa más pobre del museo", etcétera. Dicha fundamentación recurre, asimismo, a una accumulatio, un conjunto de ejemplos donde observamos cómo el cuerpo femenino de la locutora personaje es sometido a una serie de situaciones infrahumanas donde se transgrede la regla de justicia, la cual "exige la aplicación de un tratamiento idéntico a seres o a situaciones que se integran en una misma categoría" (Perelman y OlbrechtsTyteca, 2006, p. 340). Sin duda, lo que está en discusión, en este caso, es el plano de lo humano. ¿Es la mujer un ser inferior al hombre? He ahí la controversia implícita en el texto. La locutora-personaje subraya el carácter femenino de su discurso para enfrentarse a la masculinidad opresora: ella destaca su papel de madre y un contexto donde debe (léase: se ve obligada a) abortar y sangrar "todos los días del año". La menstruación y el aborto son prácticas abordadas por Blanca Varela, pero consideradas como sinónimo de imposición de la dominación masculina. Además, el acto de la madre de comer a sus hijos reduce la vida de la mujer, en una sociedad androcéntrica, a una escena de barbarie.

En la segunda parte del poema (la más propiamente argumentativa), la locutora cambia de actitud y utiliza el argumento basado en el ridículo para desacreditar al alocutario masculino. Este último es calificado de "eunuco en la puerta de los burdeles de la plaza México. Formidable pelele frente al tablero de control" (Varela, 2016, p. 88). Al hablar de la "divina baba" y del "inmaculado miembro" (Varela, 2016, p. 88) del alocutario, la locutora se sustenta en la siguiente metáfora conceptual: "el dios masculino es un eunuco y un pelele". Son dos particularidades que evidencian la fragilidad de la masculinidad hegemónica, pero también manifiestan el carácter ridículo del personaje masculino (ese "tenebroso tú" que parece omnipotente). El representante de la sociedad androcéntrica aparenta fortaleza; sin embargo, está castrado en la puerta de un burdel y carece de una personalidad propia. Es, prácticamente, un títere que no controla, en realidad, absolutamente nada.

Resulta digno de relieve el cuestionamiento de la historia bíblica de Noé narrada desde la perspectiva oficial. Varela recusa dicha narrativa justificadora de la existencia de un dios masculino que salva a la humanidad: "Escucha las trompetas de tu reino. Noé naufraga cada mañana, todo mar es terrible, todo sol es de hielo, todo cielo es de piedra" (Varela, 2016, p. 89). Frente a la historia hegemónica y legitimadora del orden androcéntrico, plantea la crisis del mencionado paradigma a través de la imagen del naufragio permanente de Noé, de manera que el cielo se concibe como una metáfora de inmovilidad y de muerte.

La historia, según Benjamin (1989), ha sido contada desde la perspectiva historicista que favorece a los vencedores y analiza el pasado como algo inmóvil. Varela considera que el relato de Noé debiera ser contado desde una óptica periférica y como un conjunto de sucesos dinámicos que se vinculan al presente marcado por la dominación masculina y la invisibilización de la mujer en la sociedad contemporánea. 
La peroración final (tercera parte del poema) está constituida solamente por la expresión siguiente: "Tu imagen en el espejo de feria me habla de una terrible semejanza". El vínculo entre la locutora personaje y el alocutario representado se ha transformado profundamente. Resulta interesante mencionar que, para Bottiroli (1993), las relaciones entre los personajes pueden ser metafóricas (de semejanza), metonímicas (por contigüidad), antitéticas (por oposición) o sinecdóquicas (parte-todo, por ejemplo). Sin duda, "Vals del ángelus", tanto en el introito como en la parte propiamente argumentativa, manifiesta una relación antitética entre ambos actores que se observa en el uso del ridículo, que emplea la locutora, para caricaturizar al personaje masculino al cual ella se dirige en tono de diatriba. Sin embargo, en la peroración final, dicho lazo antitético se transforma, paradójicamente, en una relación metafórica. Benjamin (1989) afirma que todo documento de cultura tendría que considerarse, a la vez, un documento de la barbarie. El yo percibe que el tú no solo ha impuesto su masculinidad opresora, sino que ha proyectado su reflejo en el espejo, de manera que se construye una escena imaginaria donde el yo femenino se parece al tú masculino. He ahí la aparición de otra barbarie. Ya no es la primera barbarie que implicaba la violencia física y psicológica del dios masculino sobre "la santa más pobre del museo" (Varela, 2016, p. 88). Ahora hablamos de una segunda barbarie: la que implica la negación del progreso y crea una interminable sucesión de analogías especulares, donde parece que el oprimido se parece, en cierto sentido, al opresor. Sin duda, Varela cuestiona esa normalización de la violencia cotidiana y abre una puerta a la esperanza para la transformación de los vínculos intersubjetivos entre los seres humanos.

\section{CODA}

Blanca Varela es la poeta peruana más importante de todos los tiempos. Su verbo agresivo y su gran manejo de los referentes culturales la han convertido en una autora clásica de la literatura de lengua castellana. Pensamos que releer sus versos en estos tiempos agitados es una necesidad impostergable.

\section{REFERENCIAS}

Arduini, S. (2000). Prolegómenos a una teoría general de las figuras. Universidad de Murcia. Aristóteles. (1990). Retórica (Introducción, traducción y notas por Q. Racionero). Gredos.

Benjamin, W. (1989). Discursos interrumpidos I. Taurus.

Bottiroli, G. (1993). Retorica. L'intelligenza figurale nell'arte e nella filosofia. Bollati Boringhieri.

Castañón, A. (2007). Blanca Varela: la piedad incandescente. En M. Dreyfus y R. SilvaSantisteban (Eds.), Nadie sabe mis cosas. Reflexiones en torno a la poesía de Blanca 
Varela (pp. 85-96). Congreso del Perú, Fondo Editorial.

Fernández Cozman, C. (2009). Rodolfo Hinostroza y la poesía de los años sesenta (segunda edición ampliada y corregida). Universidad de Ciencias y Humanidades.

Fernández Cozman, C. (2010). Casa, cuerpo. La poesía de Blanca Varela frente al espejo. Universidad San Ignacio de Loyola.

Fernández Cozman, C. (2012). El poema argumentativo de Wáshington Delgado. Ornitorrinco; Universidad Nacional Santiago Antúnez de Mayolo.

Fernández Cozman, C. (2014). Las técnicas argumentativas y la utopía dialógica en la poesía de César Vallejo. Universidad Ricardo Palma, Cátedra Vallejo.

Fernández Cozman, C. (2016). Interculturalidad y sujeto migrante en la poesía de Vallejo, Cisneros y Watanabe. Universidad de Lima, Fondo Editorial.

Fernández Cozman, C. (2021). Los interlocutores y campos figurativos en un poema. El caso de un poema de Vicente Huidobro y otro de Blanca Varela. ConCiencia EPG, 6(1), 76-83. https://www.researchgate.net/publication/348824524_Los_ interlocutores_y_campos_figurativos_en_un_poema_El_caso_de_un_poema_ de_Vicente_Huidobro_y_otro_de_Blanca_Varela

Gazzolo, A. M. (2007). Blanca Varela: más allá del dolor y del placer. En M. Dreyfus y R. Silva-Santisteban (Eds.), Nadie sabe mis cosas. Reflexiones en torno a la poesía de Blanca Varela (pp. 73-83). Congreso del Perú, Fondo Editorial.

Huamán, B. (2007). El estado de la cuestión y la discusión. La crítica peruana y Blanca Varela. En M. Dreyfus y R. Silva-Santisteban (Eds.), Nadie sabe mis cosas. Reflexiones en torno a la poesía de Blanca Varela (pp. 315-335). Congreso del Perú, Fondo Editorial.

Lakoff, G., y Johnson, M. (2003). Metaphors We Live By. University of Chicago Press.

Lakoff, G., y Turner, M. (1989). More than Cool Reason. A Field Guide to Poetic Metaphors. University of Chicago Press.

Meyer, M. (2013). Principia Rhetorica. Una teoría general de la argumentación. Amorrortu.

Muñoz, O. (2007). Sigiloso desvelo. La poesía de Blanca Varela. Pontificia Universidad Católica del Perú, Fondo Editorial.

Oviedo, J. M. (2007). Blanca Varela o la persistencia de la memoria. En M. Dreyfus y R. Silva-Santisteban (Eds.), Nadie sabe mis cosas. Reflexiones en torno a la poesía de Blanca Varela (pp. 35-45). Congreso del Perú, Fondo Editorial.

Paoli, R. (2007). Una visión lúcida y desencantada. En M. Dreyfus y R. Silva-Santisteban (Eds.), Nadie sabe mis cosas. Reflexiones en torno a la poesía de Blanca Varela (pp. 47-53). Congreso del Perú, Fondo Editorial. 
Parrilla Sotomayor, E. E. (2018). Argumentación y esquemas conceptuales en la poesía. Literatura y lingüística, 37. https://scielo.conicyt.cl/scielo.php?script=sci_arttext \&pid=S0716-58112018000100329

Paz, O. (2007). Destiempos de Blanca Varela. En M. Dreyfus y R. Silva-Santisteban (Eds.), Nadie sabe mis cosas. Reflexiones en torno a la poesía de Blanca Varela (pp. 29-33). Congreso del Perú, Fondo Editorial.

Perelman, Ch., y Olbrechts-Tyteca, L. (2006). Tratado de la argumentación. La nueva retórica. Gredos.

Pernot, L. (2013). La retórica en Grecia y Roma. Universidad Nacional Autónoma de México.

Portocarrero, G. (2007). Tres aproximaciones a la poesía de Blanca Varela. En M. Dreyfus y R. Silva-Santisteban (Eds.), Nadie sabe mis cosas. Reflexiones en torno a la poesía de Blanca Varela (pp. 297-312). Congreso del Perú, Fondo Editorial.

Reisz, S. (2007). Blanca Varela en la línea mortal del equilibrio. En M. Dreyfus y R. SilvaSantisteban (Eds.), Nadie sabe mis cosas. Reflexiones en torno a la poesía de Blanca Varela (pp. 269-278). Congreso del Perú, Fondo Editorial.

Rodríguez Gutiérrez, M. (2008). La metáfora animal. En torno al bestiario de Blanca Varela. Revista de Crítica Literaria Latinoamericana, 68, 211-223.

Salazar, I. (2012). Del ángel y el animal en la poesía de Blanca Varela. Bulletin Hispanique, 114-2, 671-701.

Silva-Santisteban, R. (2007). Una jerga de aguas negras. Lectura a dos voces de El libro de barro. En M. Dreyfus y R. Silva-Santisteban (Eds.), Nadie sabe mis cosas. Reflexiones en torno a la poesía de Blanca Varela (pp. 269-278). Congreso del Perú, Fondo Editorial.

Sobrevilla, D. (2007). La poesía como experiencia. Una primera mirada a la Poesía reunida 1949-1983, de Blanca Varela. En M. Dreyfus y R. Silva-Santisteban (Eds.), Nadie sabe mis cosas. Reflexiones en torno a la poesía de Blanca Varela (pp. 55-71). Congreso del Perú, Fondo Editorial.

Suárez, M. (2003). Espacio pictórico y espacio poético en la obra de Blanca Varela. Verbum.

Toulmin, S. (2006). The Uses of Argument. Cambridge University Press.

Varela, B. (2016). Poesía reunida 1949-2000. Casa de Cuervos; Sur, Librería Anticuaria. 